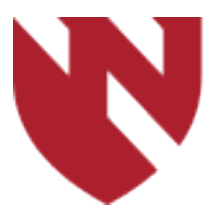

\title{
Effectiveness of Advanced Pupil Simulator for Teaching Pupillary Abnormalities: A Pilot Study on Medical Students, Neurology, and Ophthalmology Residents
}

\author{
Jideofor K. Ndulue \\ University of Nebraska Medical Center \\ Deepta Ghate \\ University of Nebraska Medical Center \\ Kedar Sachin \\ University of Nebraska Medical Center
}

Tell us how you used this information in this short survey.

Follow this and additional works at: https://digitalcommons.unmc.edu/gmerj

Part of the Higher Education Commons, and the Medicine and Health Sciences Commons

\section{Recommended Citation}

Ndulue, J. K., Ghate, D., , Sachin, K. Effectiveness of Advanced Pupil Simulator for Teaching Pupillary Abnormalities: A Pilot Study on Medical Students, Neurology, and Ophthalmology Residents. Graduate Medical Education Research Journal. 2019 Dec 13; 1(1).

https://digitalcommons.unmc.edu/gmerj/vol1/iss1/30

This Conference Proceeding is brought to you for free and open access by DigitalCommons@UNMC. It has been accepted for inclusion in Graduate Medical Education Research Journal by an authorized editor of DigitalCommons@UNMC.For more information, please contact digitalcommons@unmc.edu. 
Effectiveness of Advanced Pupil Simulator for Teaching Pupillary Abnormalities: A Pilot Study on Medical Students, Neurology, and Ophthalmology Residents

\section{Creative Commons License}

\section{(c) (i) $\Theta($}

This work is licensed under a Creative Commons Attribution-Noncommercial-No Derivative Works 4.0 License. 


\section{Stereotactic Body Radiotherapy versus Non-Radiotherapeutic Ablative Procedures for Early Stage Non-Small Cell Lung Cancer \\ Michael J Baine*, Richard Sleightholm*, Beth Neilsen, David Oupický, Lynette M Smith, Vivek Verma, Chi Lin}

*These authors contributed equally

Mentor: Chi Lin

Program: Radiation Oncology

Introduction: Despite the fact that stereotactic body radiation therapy (SBRT) is the only recommended first-line therapy for inoperable early stage NSCLC, several thermal ablative procedures (TAPs) are available. Outcomes from these procedures, and how they compare to SBRT, are scarce. We sought to evaluate the comparative efficacy of SBRT versus TAPs using the National Cancer Database (NCDB).

Methods: The NCDB (2004-2014) was queried for early stage NSCLC patients who did not undergo surgical resection. Treatment- specific inclusion criteria were applied to select for patients as receiving either TAPs or SBRT. Univariate logistic regression, Cox proportional hazard modeling, and Kaplan-Meier (KM) curves were performed. Propensity matching was performed using a modified Greedy $8 \rightarrow \mathrm{n}$ matching 1:1 algorithm.

Results: 27,734 patients were analyzed; 26,725 underwent SBRT and 1,009 underwent IR-procedures. Patients who received SBRT were older and more likely to have clinical stage 1B disease. Despite this, SBRT was associated with longer median overall survival (OS) (37.7 vs 33.5 months, $\mathrm{p}=0.001$ ) and 1, 2, and 5 year OS than the IR cohort at $86.7 \%$ vs
$83.1 \%, 67.5 \%$ vs $62.7 \%$, and $30.6 \%$ vs $26.9 \%$, respectively $(\mathrm{p}=0.001)$. Upon propensity matching, the improved OS with SBRT remained with a median OS of 40.4 months vs 33.4 months and 1, 2, and 5 year OS of $89.0 \%$ vs $82.9 \%, 69.7 \%$ vs $62.7 \%$, and $34.4 \%$ vs $26.4 \%$, respectively $(\mathrm{p}=0.0033)$.

Conclusions: Despite being associated with multiple poor prognostic features, SBRT was associated with higher OS over TAPs for treatment of non-operative patients diagnosed with early-stage NSCLC.

https://doi.org/10.32873/unmc.dc.gmerj.1.1.028

\section{Non Neurofibromatosis-1 Scalp Malignant Nerve Sheath Sarcoma with Non-Confluent Parotid Metastasis: Rare Case and Review of Literature Alejandro Wolf, Chandra Srinivasa}

Mentor: Chandra Srinivasa

Program: Pathology

Objective: To delineate a distinct clinical, pathological, immunohistochemical distinguishing features, and management of malignant peripheral nerve sheath tumor of the scalp.

Methods: We performed pathology evaluation of specimen and conduct review of the literature regarding the clinical presentation, diagnosis, treatment modalities, and outcome for MPNSTs in this anatomic location.

Results: In patients with neurofibromatosis type 1 (NF1), approximately 5 in 10 MPNSTs arise from neurofibromas. Overall MPNST has a prevalence of $0.001 \%$ in the general population. Only a few cases of MPNSTs have been reported to have originated in the skin accounting for approximately $2-9 \%$ of all MPNSTs. Of those, $50 \%$ are in the head and neck, with the scalp as the main location. Although there are only a few reports of MPNSTs arising primarily in the parotid gland, apart from our case, there are only two previous cases of an MPNST metastasizing to the parotid gland. None of the cases with metastasis to the parotid appears to have had neurofibromatosis.

Conclusion: The superficial MPNSTs derive from cutaneous neurofibromas or small peripheral nerves, and are markedly aggressive with rapid invasive growth, recurrence after excision, and early hematogenous dissemination. Immunohistochemically, S100 staining is positive in up to $50 \%$. There is no genetic difference between NF1-associated and sporadic tumors. Surgical treatment with margins greater or equal to $2 \mathrm{~cm}$ and adjuvant radiation must be considered as a standard treatment. Negative-pressure wound VAC therapy, fascial or muscular flaps with microvascular anastomosis are ideal for reconstruction.

https://doi.org/10.32873/unmc.dc.gmerj.1.1.029

\section{Effectiveness of Advanced Pupil Simulator for Teaching Pupillary Abnormalities: A Pilot Study on Medical Students, Neurology and Ophthalmology Residents \\ Jideofor K Ndulue, Deepta Ghate, Kedar Sachin}

Mentors: Deepta Ghate, Kedar Sachin

Program: Truhlsen Eye Institute

Background: We recently designed a virtual reality-based application, Advanced Pupil Simulator $^{\circledR}$, and herein report the results of training with this device on trainee selfperceived confidence and competence to perform pupillary examination.

Methods: Participants included 145 trainees (126 first-year medical students, 15 neurology and 4 ophthalmology residents). All trainees reviewed an online power-point module and practiced pupillary examination in groups of 3 assigned to a simulator and expert faculty for 30 minutes. All trainees completed a Likerttype questionnaire $(1=$ not confident, $5=$ very confident) assessing confidence to perform pupillary examination before and after the study. All trainees were objectively assessed for knowledge, comprehension, application and analysis by the faculty. The difference in pre-and post-training confidence was tested using Wilcoxon sign rank test. Group differences in objective scores were tested using Fischer's exact test.

Results: 97\% (122) students and 10 (52\%) residents reported improved confidence in performing pupil examination following training. 80\% (101) students and 89\% (17) residents were able to correctly list and demonstrate all steps in the pupil examination. $77 \%$ (97) students and 74\% (14) residents 
correctly identified relative afferent pupillary defect (RAPD) while 88\% (111) students and $95 \%$ (18) residents correctly identified Horner's syndrome. 97\% (123) students and 95\% (18) residents correctly used appropriate pharmacological drops to confirm Horner's pupil. Post training, students reported improved confidence in identification of all 5 pupillary abnormalities $(\mathrm{p}=0.00)$, while residents reported most improvement in the confidence in diagnosing Adie pupil $(p=0.00)$

\section{When It's Not Just Hypothyroidism} Preethi Polavarapu, Whitney S Goldner

Mentor: Whitney S Goldner

Program: Diabetes, Endocrinology, and Metabolism

Background: Autoimmune Polyglandular Type II Syndrome is characterized by Autoimmune Thyroid disease, Type 1 Diabetes, and Primary Adrenal Insufficiency. Twenty percent of the persons with APS II can simultaneously present with symptoms of adrenal insufficiency and thyroid disease. In these patients, replacement of thyroid hormone before cortisol can precipitate adrenal crisis.

Methods: A middle-aged patient presented to the endocrine clinic with fatigue, unintentional weight loss, nausea, abdominal pain and syncope. Initial labs with the PCP showed elevated TSH at $6.6 \mathrm{mcIU} / \mathrm{ml}$, normal T4 $0.8 \mathrm{ng} / \mathrm{dl}$ consistent with subclinical hypothyroidism. The patient was started on levothyroxine but symptoms worsened despite and using pharmacologic agent to confirm anisocoria $(\mathrm{p}=0.00)$.

Conclusion: All trainees showed significant improvement in confidence and competence in pupillary examination after using the APS. Virtual-reality based practical training can shorten time to competency for critical medical examination techniques.

https://doi.org/10.32873/unmc.dc.gmerj.1.1.030 normalization of thyroid function tests. The patient presented to us for further evaluation. On examination the patient was tan, blood pressure was 100/56mmHg. Labs showed Sodium $133 \mathrm{mmol} / 1$, Potassium $4.5 \mathrm{mmol} / \mathrm{l}$, TSH $2.5 \mathrm{mcIU} / \mathrm{ml}$, T4 $1 \mathrm{ng} / \mathrm{dl}$, Bicarbonate $24 \mathrm{mmol} / \mathrm{l}$. Given the patient's worsening symptoms despite normalization of thyroid function tests and electrolyte abnormalities she was evaluated for adrenal insufficiency.

Results: Labs showed random cortisol level $0.4 \mathrm{mcg} / \mathrm{dl}$, ACTH stimulation showed cortisol level at 0.30, 60 minutes was $<0.4$ $\mathrm{mcg} / \mathrm{dl}$, ACTH level $951 \mathrm{pg} / \mathrm{ml}$, aldosterone $<3 \mathrm{ng} / \mathrm{dl}$, renin $0.5 \mathrm{ng} / \mathrm{ml} / \mathrm{hr}$ consistent with adrenal insufficiency. Levothyroxine was held for 1 week, hydrocortisone and fludrocortisone was initiated and symptoms improved dramatically.

Conclusion: Multiple endocrinopathies can present in persons with APS II. This

\section{Papillary Thyroid Cancer in the Ovaries? A Case of Struma Ovarii Sapna Raghunathan, Anery Patel}

Mentor: Anery Patel

Program: Diabetes, Endocrinology, and Metabolism

Background: Struma ovarii is a specialized teratoma predominantly composed of mature thyroid tissue. Accounts for 5\% of all teratomas. They could be benign or malignant, compose $>50 \%$ of overall tissue, to be categorized as struma ovarii. Clinical and biochemical findings of hyperthyroidism are uncommon. Here, we present a case of struma ovarii with co-existing thyroid nodules.

Methods: This is a middle-aged patient with no past medical history, who presented to the PCP with dysmenorrhea and menorrhagia. The patient was found to have a complex 8 $\mathrm{cm}$ ovarian cyst with normal CA-125. The patient underwent a right oophorectomy and bilateral salpingectomy for removal of the mass. Pathology showed the ovarian cyst wall containing thyroid tissue, mostly benign, but with two small foci of follicular variant of papillary carcinoma in the background of struma ovarii.

Initial thyroid function tests showed a TSH of 4.44 and thyroglobulin levels within normal range. Ultrasound of the thyroid gland, showed a $1 \mathrm{~cm}$ nodule with a 5-20\% risk of malignancy, but too small to biopsy. Considering the need to monitor disease recurrence with tumor markers, the patient underwent a total thyroidectomy.

Results: Pathology of the thyroid gland showed lymphocytic thyroiditis with no evidence of malignancy.

Conclusions: Thyroid cancer metastatic to the ovary can be confused with true struma ovarii. Primary thyroid cancer rarely metastasizes to the ovary, and in these cases, the ovary does not have teratomatous features. patient presented with both Primary Adrenal Insufficiency and Primary Hypothyroidism. Symptoms of hypothyroidism and adrenal insufficiency can be nonspecific, so a high index of suspicion is needed to evaluate for other causes if symptoms worsen after initiating levothyroxine.

https://doi.org/10.32873/unmc.dc.gmerj.1.1.031

Thyroidectomy helps to monitor recurrence, as thyroglobulin can then be produced only by the tumor.

https://doi.org/10.32873/unmc.dc.gmerj.1.1.032 